\title{
Effect of Glycyrrhizic Acid on Scopolamine-Induced Cognitive Impairment in Mice
}

\author{
Ju Yeon Ban ${ }^{1, *}$, Hyun Kyung Park ${ }^{2, *}$, Su Kang Kim ${ }^{3}$ \\ ${ }^{1}$ Department of Dental Pharmacology, College of Dentistry, Dankook University, Cheonan, Korea \\ ${ }^{2}$ Department of Emergency Medicine, Seoul Medical Center, Seoul, Korea \\ ${ }^{3}$ Department of Biomedical Laboratory Science, Catholic Kwandong University, Gangneung, Korea
}

Purpose: Cognitive impairment is one of the main symptoms of Alzheimer disease and other dementias. Glycyrrhiza uralensis is a natural product that has a protective effect against cognitive impairment. In this study, we investigated whether glycyrrhizic acid, among the main bioactive components of Glycyrrhiza uralensis, has a neuroprotective effect on scopolamine-induced cognitive impairment.

Methods: Twenty-week-old male Institute of Cancer Research mice were used in this study. The scopolamine-induced cognitive impairment mice model was used. Glycyrrhizic acid was orally administered to mice once daily for 21 days, while scopolamine $(1 \mathrm{mg} / \mathrm{kg})$ treatment was delivered 30 minutes before behavioral tests. Donepezil $(2 \mathrm{mg} / \mathrm{kg})$ was used as a positive drug control. To evaluate the effect of glycyrrhizic acid, the following assessments were performed on hippocampal tissue: Y-maze test, acetylcholinesterase activity, antioxidant enzymes' activity (superoxide dismutase, catalase). Western blotting for phosphor-extracellular signal-regulated kinase, P38, and c-Jun NH2-terminal kinase was conducted.

Results: We found that glycyrrhizic acid administration significantly improved scopolamine-induced cognitive impairment in the Y-maze test. The acetylcholinesterase activity, superoxide dismutase, and catalase activity in the glycyrrhizic acid-treated group showed a significant reversal of cognitive impairment compared with the scopolamine-treated group.

Conclusions: Our results suggest that glycyrrhizic acid has a neuroprotective effect on cognitive function in scopolamine-induced cognitive impairment.

Keywords: Memory; Scopolamine; Glycyrrhizic acid

- Fund/Grant Support: The present research was conducted by the research fund of Dankook University in 2017.

- Research Ethics: All experiments were conducted in accordance with the guidelines from the Korean National Health Institute of Health Animal

Facility and experimental protocol were approved by the Animal Care Committee of the Animal Center at Dankook University (DKU-20-013).

- Conflict of Interest: No potential conflict of interest relevant to this article was reported.

\footnotetext{
- HIGHLIGHTS

- We investigated the neuro-protective effect of glycyrrhizic acid among main bioactive components of Glycyrrhiza uralensis.

- The glycyrrhizic acid pretreatment has increased memory and enhanced antioxidant-related enzymes.

- The present study suggested that the glycyrrhizic acid has a neuroprotective effect on cognitive function in the scopolamine-induced cognitive impairment mice model.
}

Corresponding author: Su Kang Kim (iD https://orcid.org/0000-0001-6178-8514 Department of Biomedical Laboratory Science, Catholic Kwandong University, 24 Beomil-ro 579beon-gil, Gangneun 25601, Korea

E-mail: flyexcel@hanmail.net / Tel: +82-33-649-7404 / Fax: +82-33-649-7404 ${ }^{*} J u$ Yeon Ban and Hyun Kyung Park contributed equally to this study as co-first authors. Submitted: April 5, 2020 / Accepted after revision: May 7, 2020
This is an Open Access article distributed under the terms of the Creative Commons Attribution Non-Commercial License (http://creativecommons.org/licenses/by-nc/4.0/) which permits unrestricted non-commercial use, distribution, and reproduction in any medium, provided the original work is properly cited. 


\section{INTRODUCTION}

Cognitive impairment is defined as a condition, associated with an increase in memory loss, relative to age. The level of cognitive impairment cannot yet be characterized as dementia, consisting instead of a level of impairment located between the normal and dementia stages [1]. Many studies have suggested that individuals with cognitive impairment are more likely to develop dementia than normal subjects [2]. Dementia is a deterioration of cognitive abilities caused by functional abnormalities in the brain. Dementia can also be classified as a degenerative disease, of which Alzheimer disease (AD) is the most common disease [3]. A characteristic feature of dementia is impaired memory. It is estimated that 24.3 million people worldwide have dementia, and one new patient is diagnosed every 7 seconds [4]. In Korea, the incidence of dementia is also increasing significantly. The number of patients with dementia is expected to double every 20 years by 2050 [5]. Dementia not only interferes with normal social and occupational life of the elderly but is also associated with a substantial social and economic burden. Germany estimates that dementia will account for $74 \%$ of the total social cost and $36 \%$ of the total social cost of the elderly [6]. Therefore, numerous studies have been conducted on the mechanism and development of therapeutic agents for dementia.

It is known that cholinergic dysfunction in the brain is involved in the development of dementia [7] and that acetylcholinesterase (AChE) inhibitors are used for the treatment of cognitive impairment [8]. Therefore, scopolamine, a drug that increases the activity of AChE in the breakdown of acetylcholine $(\mathrm{ACh})$ at the nerve ending and induces memory loss for a short period of time, is widely used to study cognitive impairment in animal models [9].

Glycyrrhiza uralensis (G. uralensis) is a well-known traditional herbal medicine and has long been used as an herbal and natural sweetener in Asia [10]. Licorice roots have traditionally been used for digestive diseases, skin diseases, hepatitis, and respiratory diseases [11]. Studies on the bioactive compounds of G. uralensis have revealed its antiviral, anti-inflammatory, and antioxidant properties [12-14]. The main bioactive components of G. uralensis are triterpene saponins and various types of flavonoids, including glycyrrhetinic acid, glycyrrhizic acid, liquiritigenin, isoliquiritigenin, liquiritin, and licochalcone A. These components possess various biological properties [11], with many previous studies reporting their neuroprotective ef- fects. Glycyrrhizic acid and glycyrrhizin are saponins contained in G. uralensis. Glycyrrhizic acid inhibits complement-dependent cytotoxicity and prevents astrocyte death [15]. Glycyrrhizin, also present in the roots and rhizomes, attenuates kainic acid-induced neuronal cell death through the mechanism of anti-inflammatory and antiexcitotoxic effects [16]. Isoliquiritigenin, a flavonoid contained in Glycyrrhiza uralensis, interferes with apoptosis in dopaminergic neurons [17], while liquiritigenin inhibits neurotoxicity in rat hippocampal neurons [18].

This study examined the effect of glycyrrhizic acid on scopolamine-induced cognitive impairment using behavioral models and investigated the neuroprotective effect of glycyrrhizic acid on brain tissue and changes in biological parameters.

\section{MATERIALS AND METHODS}

\section{Preparation of the Glycyrrhizic Acid}

Glycyrrhizic acid ammonium salt $\left(\mathrm{C}_{42} \mathrm{H}_{62} \mathrm{O}_{16} \cdot \mathrm{NH}_{3}\right.$, molecular weight, 839.96) from glycyrrhiza root was obtained from Sigma-Aldrich (Sigma Chemical Co., St. Louis, MO, USA).

\section{Animals}

The animals used in this study were 20-week-old male Institute of Cancer Research mice (RaonBio Inc., Seoul, Korea), and average body weight was $30 \pm 5 \mathrm{~g}$. The animal room was maintained at a temperature of $22^{\circ} \mathrm{C} \pm 2^{\circ} \mathrm{C}$ and a relative humidity of $40 \%-70 \%$, and the room lighting was bright for 12 hours and dark for 12 hours. All experiments were conducted in accordance with the guidelines from the Korean National Health Institute of Health Animal Facility and experimental protocol was approved by the Animal Care Committee of the Animal Center at Dankook University (DKU-20-013).

\section{Treatments}

In present study, mice were randomly divided into 4 groups (10 mice in each group): the control group (saline treated), the scopolamine group ( $1 \mathrm{mg} / \mathrm{kg} /$ day scopolamine treated), the donepezil group $(2 \mathrm{mg} / \mathrm{kg} /$ day donepezil and $1 \mathrm{mg} / \mathrm{kg} /$ day scopolamine treated), and the glycyrrhizic acid group (10 or $20 \mathrm{mg} /$ $\mathrm{kg} /$ day glycyrrhizic acid and $1 \mathrm{mg} / \mathrm{kg} /$ day scopolamine treated). The mice were orally administered with each drug during 3 weeks. Glycyrrhizic acid was dissolved in saline and administered during 21 days, prior to training for the Y-maze test and passive avoidance test. Scopolamine was dissolved in saline and was injected 30 minutes before the trial. 


\section{Y-maze Test}

The Y-maze test is used to measure immediate spatial working memory, a form of short-term memory. The Y-maze is a threearm horizontal maze $\left(40 \mathrm{~cm} \times 4.5 \mathrm{~cm} \times 12 \mathrm{~cm}, 120^{\circ}\right.$ apart). Mice were initially placed in one arm among 3 arms. The arm entry sequence and the number of arm entries were recorded manually for each mouse within 8 minutes. An alternation was defined as an entry into all 3 arms consecutively (for example, $\mathrm{ABC}, \mathrm{BCA}$, or $\mathrm{CAB})$. One hour before the Y-maze test, mice were treated with glycyrrhizic acid (10 or $20 \mathrm{mg} / \mathrm{kg}$ ) or donepezil ( $2 \mathrm{mg} / \mathrm{kg})$ as a positive control, and 30 minutes later, memory impairment was induced by administration of scopolamine (1 mg/kg, intraperitoneally). Control animals received vehicle only. Maze arms were thoroughly cleaned with $70 \%$ alcohol to remove residual odors. Percentage alternation was determined by the following equation: $\%$ alternation $=[$ (total of number of alternations) $/($ total arm entries -2$)] \times 100$.

\section{AChE Activity Analysis}

According to the manufacturer's protocols, the level of AChE activity was determined using an acetylcholinesterase assay kit (Abcam, Cambridge, UK). The 5,5-dithiobis-(2-nitrobenzoic acid) (DTNB), ACh, and AChE were prepared from stock solutions. To measure the effect of glycyrrhizic acid on AChE activity on hippocampal tissue, samples were weighed (200 mg of the brain homogenate), and protein lysis buffer (iNtRON Biotechnology Inc., Seoul, Korea) was added to each tube. Briefly, the Ach reaction mixture (assay buffer, DNTB solution, and Ach stock solution) was added in tissue lysates. The final reaction was read using an absorbance microplate reader at $410 \mathrm{~nm}$ (Multiskango, ThermoFisher, Seoul, Korea).

\section{Measurement of SOD and CAT Activities}

The hippocampal tissue was prepared in protein lysis buffer [19] and centrifuged at 12,000 rpm for 10 minutes. Additionally, the supernatant was used in the assays of superoxide dismutase (SOD) and catalase (CAT) activities according to the manufacture's protocols. The SOD activity was measured by the ability to inhibit the formation of formazan dye, with maximum absorbance at $450 \mathrm{~nm}$. The formazan dye was produced by monosodium salt reacting with $\mathrm{O}_{2}$ from the xanthine oxidase system. The CAT activity was determined at 20-nm utility of the peroxidatic function of CAT. The activities of SOD and CAT were expressed as \% of control.

\section{Western Blotting}

The hippocampal tissue was prepared in protein lysis buffer containing protease inhibitors (phenylmethylsulfonylfluoride, ethylenediaminetetraacetic acid, and pep statin A, leupeptin, and aprotinin) [19]. Each protein concentration was determined using the Bradford method. All the samples were heated for 5 minutes at $95^{\circ} \mathrm{C}$, incubated on ice for 5 minutes, and centrifuged at 14,000 rpm for 10 minutes to remove insoluble materials. Equal amounts of protein $(20 \mu \mathrm{g})$ were loaded in the sodium dodecyl sulfate-polyacrylamide gel. After electrophoresis, the protein was transferred onto a nitrocellulose blotting membrane. The membrane was blocked in 5\% skim milk, and then incubated with primary antibodies (diluted 1:1,000): extracellular signal-regulated kinase (ERK), phospho-ERK, p38, phospho-p38, c-Jun NH2-terminal kinase (JNK), phosphor-JNK (Cell Signaling Technology, Beverly, MA, USA) [20,21]. After incubation with horseradish-peroxidase-conjugated secondary antibody (Cayman Chemical Co., Ann Arbor, MI, USA), protein bands were developed using an enhanced chemiluminescence kit, and then detected using MicroChemi 4.2 (MicroChemi 4.2; DNR Bio imaging system Ltd., Neve Tamin, Israel), equipped with Gelcapture software.

\section{Statistical Analyses}

The values were indicated as the mean \pm standard error. Significant differences among the groups were statistically analyzed using the 1-way analysis of variance, followed by a nonparametric post Tukey test. All P-values were 2-tailed. Results were considered statistically significant at values of $\mathrm{P}<0.05$. All statistical analyses were analyzed using IBM SPSS Statistics ver. 22.0 (IBM Co., Armonk, NY, USA).

\section{RESULTS}

\section{Effects of Glycyrrhizic Acid on Y-Maze Test}

Fig. 1 shows the effects of glycyrrhizic acid pretreatment (10 or $20 \mathrm{mg} / \mathrm{kg}$ ) on spontaneous alternation behavior in the Y-maze test. The scopolamine $(1 \mathrm{mg} / \mathrm{kg})$ injection was associated with a significant decrease in short-term memory performance, as indicated by a decreased spontaneous alternation percentage, compared with the control group $(\mathrm{P}<0.001)$. Both doses of glycyrrhizic acid pretreatment (10 or $20 \mathrm{mg} / \mathrm{kg}$ ) significantly improved the spontaneous alternation percentage, which was decreased by scopolamine (Fig. 1A). However, the improvement in short-term memory could not be attributed to locomo- 

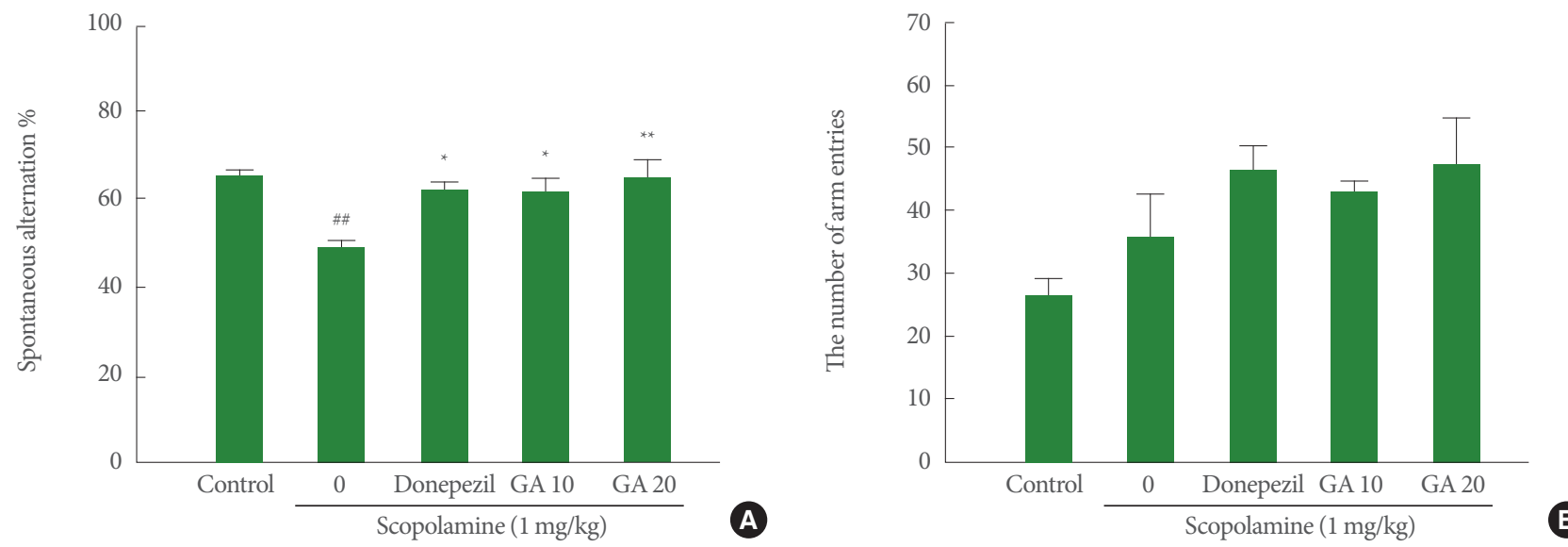

Fig. 1. Effect of glycyrrhizic acid on spontaneous alternation percentage (A) and number of arm entries (B) in the Y-maze test. Values are expressed as mean \pm standard error of the mean. GA $10,10 \mathrm{mg} / \mathrm{kg} /$ day glycyrrhizic acid; GA $20,20 \mathrm{mg} / \mathrm{kg} /$ day glycyrrhizic acid. ${ }^{* *} \mathrm{P}<0.01$ compared to control group. ${ }^{*} \mathrm{P}<0.05$ compared to scopolamine-treated group. ${ }^{*} \mathrm{P}<0.01$ compared to scopolamine-treated group.

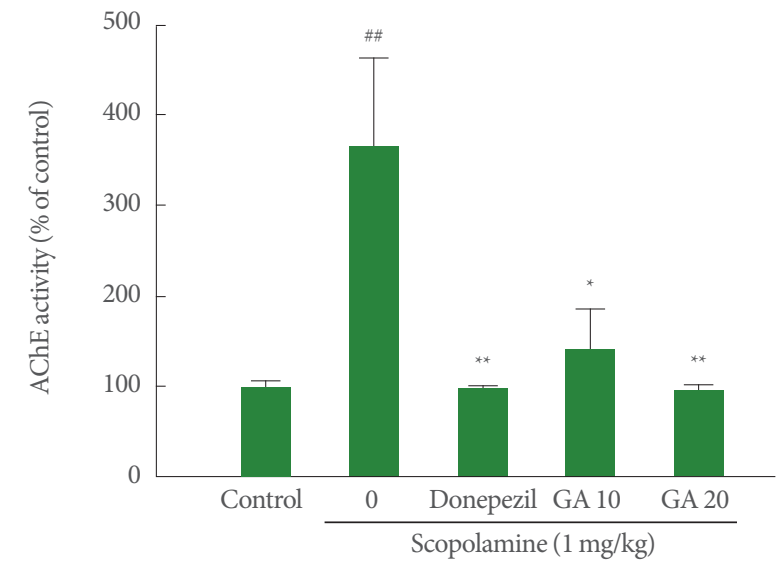

Fig. 2. Effect of glycyrrhizic acid on acetylcholinesterase activity in the brain of scopolamine-treated mice. Acetylcholinesterase activity was measured after the behavioral experiments. Values are expressed as mean \pm standard error. GA $10,10 \mathrm{mg} / \mathrm{kg} /$ day glycyrrhizic acid; GA $20,20 \mathrm{mg} / \mathrm{kg} /$ day glycyrrhizic acid. ${ }^{* *} \mathrm{P}<0.01$ compared to control group. ${ }^{*} \mathrm{P}<0.05$ compared to scopolamine-treated group. ${ }^{* *} \mathrm{P}<0.01$ compared to scopolaminetreated group. $\mathrm{AChE}$, acetylcholinesterase.

tor activity, as presented by the number of arm entries, since no significant differences between groups were observed (Fig. 1B). The present results suggest that glycyrrhizic acid pretreatment has a beneficial effect on short-term memory.

\section{Effects of Glycyrrhizic Acid on Brain AChE Activity in Scopolamine-Treated Mice}

As shown in Fig. 2, scopolamine treatment significantly increased AChE activity in the brain when compared with the control group $(\mathrm{P}<0.01)$. Pretreatment with donepezil $(2 \mathrm{mg} /$ $\mathrm{kg}$ ) was associated with a significant reduction of $\mathrm{AChE}$ activity in the brain as compared with the scopolamine-treated group $(\mathrm{P}<0.01)$. The glycyrrhizic acid pretreatment $(10$ or $20 \mathrm{mg} / \mathrm{kg})$ also revealed a significant reduction in AChE activity $(\mathrm{P}<0.05$ or $\mathrm{P}<0.01$, respectively).

\section{Effects of Glycyrrhizic Acid on SOD and CAT Activity}

Regarding SOD activity, the scopolamine-treated group was associated with a significant decrease in the SOD activity compared with the control group $(\mathrm{P}<0.01)$. Meanwhile, pretreatment with glycyrrhizic acid (10 or $20 \mathrm{mg} / \mathrm{kg}$ ) was associated with a significant increase in SOD activity compared with the scopolamine-treated group $(\mathrm{P}<0.05$ or $\mathrm{P}<0.01$, respectively). The donepezil-pretreated group also displayed a significant increase in the SOD activity $(\mathrm{P}<0.01)$ (Fig. $3 \mathrm{~A})$.

As shown in Fig. 3B, the CAT activity did not differ significantly among the groups $(\mathrm{P}>0.05)$. However, the CAT activity showed an increased tendency in the donepezil- and glycyrrhizic acid-pretreated groups compared with the scopolaminetreated group. Moreover, the CAT activity in the donepezil- and glycyrrhizic acid-pretreated groups was higher than in the control group.

\section{Effects of Glycyrrhizic Acid on Expression of phospho- MAPKs}

In order to study the possible action mechanisms of the antioxidative stress activity of glycyrrhizic acid $(20 \mathrm{mg} / \mathrm{kg})$, activation of the mitogen-activated protein kinase (MAPK) signaling 

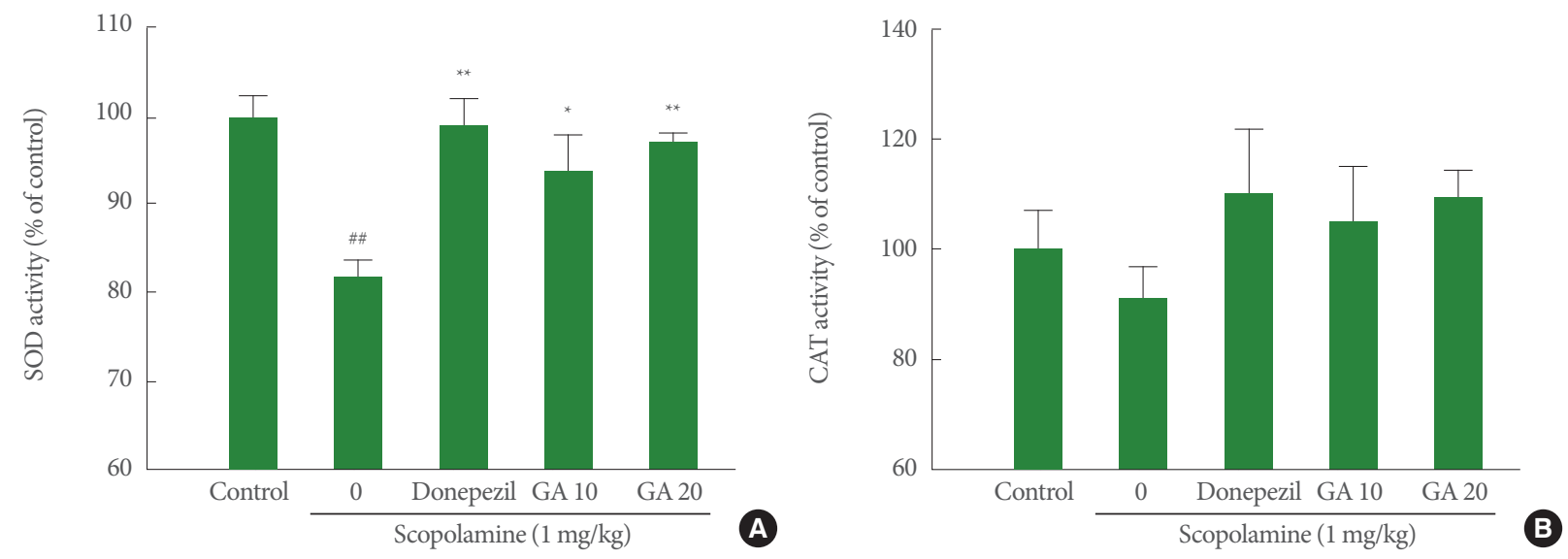

Fig. 3. Effects of glycyrrhizic acid on superoxide dismutase (A) and catalase activity (B). Values are expressed as mean \pm standard error. GA $10,10 \mathrm{mg} / \mathrm{kg} /$ day glycyrrhizic acid; GA $20,20 \mathrm{mg} / \mathrm{kg} /$ day glycyrrhizic acid. ${ }^{* \#} \mathrm{P}<0.01$ compared to control group. ${ }^{*} \mathrm{P}<0.05$ compared to scopolamine-treated group. ${ }^{\star \star} \mathrm{P}<0.01$ compared to scopolamine-treated group. SOD, superoxide dismutase; CAT, catalase.
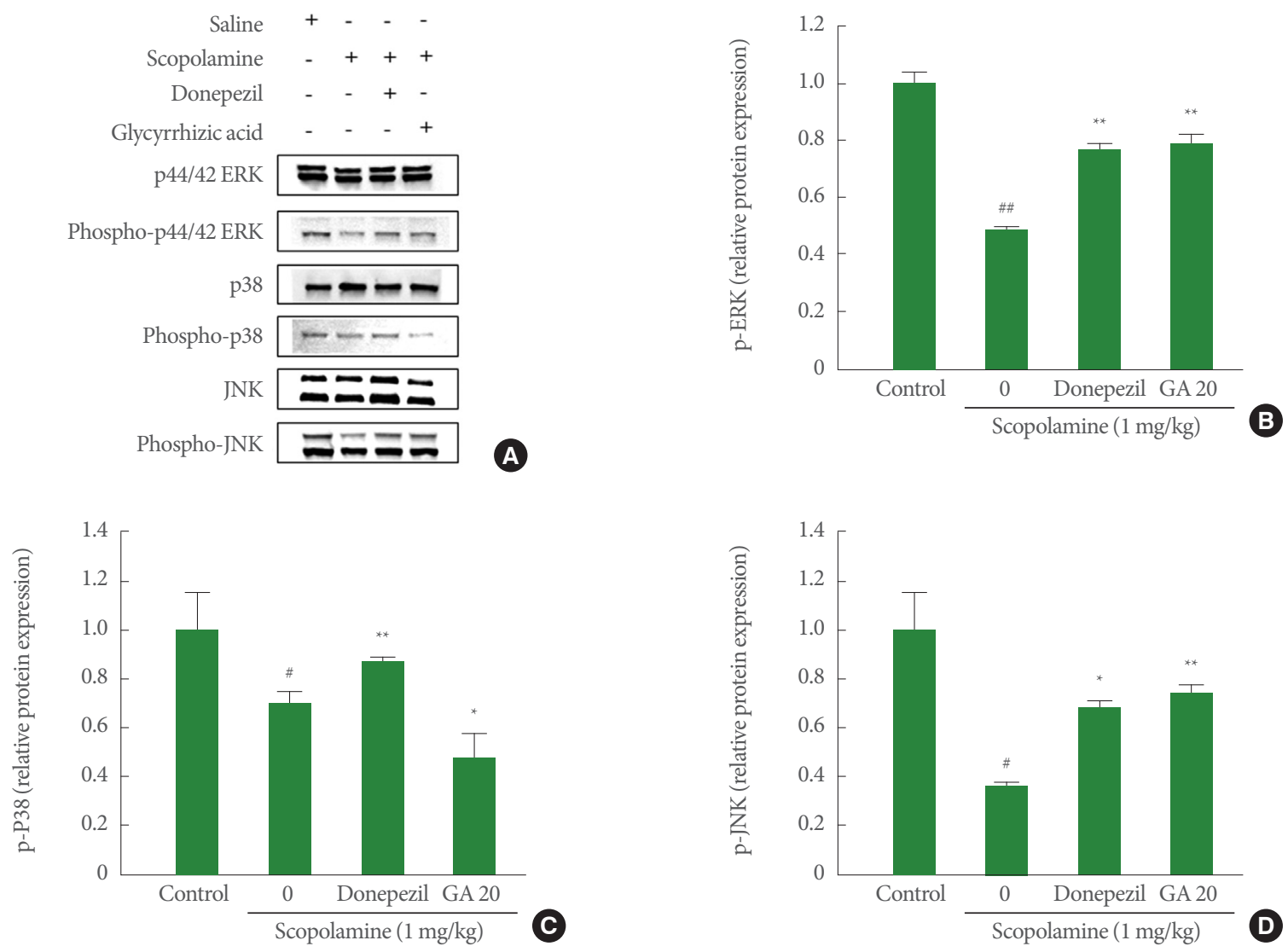

Fig. 4. Western blot of phospho-extracellular signal-regulated kinase (phospho-ERK), phospho-P38, phospho-c-Jun NH2-terminal kinase (phospho-JNK), ERK, P38, and JNK in hippocampal tissue. (A) Western blot analysis of phospho-ERK, phospho-P38, phospho-JNK, ERK, P38, and JNK proteins in each group. (B) Quantitative analysis of phospho-ERK protein expression. (C) Quantitative analysis of phospho-38 protein expression. (D) Quantitative analysis of phospho-JNK protein expression. Values are expressed as mean \pm standard error. GA $20,20 \mathrm{mg} / \mathrm{kg} /$ day glycyrrhizic acid. ${ }^{*} \mathrm{P}<0.05$ compared to control group. ${ }^{* \#} \mathrm{P}<0.001$ compared to control group. ${ }^{*} \mathrm{P}<0.01$ compared to scopolamine group. ${ }^{*} \mathrm{P}<0.01$ compared to scopolamine group. 
pathway, including p38, JNK, and ERK, was analyzed by western blot. As a shown in Fig. 4A-D, comparing with the control group, the expressions of phospho-ERK, phospho-p38, and phospho-JNK in the scopolamine group were significantly decreased to $0.48 \pm 0.01,0.71 \pm 0.04$, and $0.36 \pm 0.01$, respectively. However, glycyrrhizic acid $(20 \mathrm{mg} / \mathrm{kg})$ could significantly increase the expressions of phospho-ERK (mean of relative protein expression \pm standard error, $0.79 \pm 0.03$ ) and phospho-JNK $(0.73 \pm 0.04)$. The present results suggest that the antioxidative stress ability of glycyrrhizic acid $(20 \mathrm{mg} / \mathrm{kg})$ is involved in the MAP kinase pathway. Thus, these findings indicate that glycyrrhizic acid $(20 \mathrm{mg} / \mathrm{kg})$ increases phosphorylation of ERK and JNK proteins.

\section{DISCUSSION}

Based on the literature, G. uralensis has several bioactive components, including glycyrrhetinic acid, glycyrrhizic acid, liquiritigenin, isoliquiritigenin, liquiritin, and licochalcone A. In previous study, Ahn et al. [22] reported that G. uralensis has a protective effect on the cognitive deficits and oxidative stress induced by the administration of amyloid beta protein $(\mathrm{A} \beta)_{25-35}$ in mice models. Indeed, they showed that G. uralensis has a protective effect against cognitive impairment in $\mathrm{AD}$ mice models and is mediated by antioxidant action (AChE and CAT enzymes) against oxidative stress [22].

In the present study, we examined the effects of glycyrrhizic acid on the Y-maze test to assess short-term memory and biochemical functions of scopolamine-induced cognitive impairment in mice. In previous studies, glycyrrhizic acid ameliorated cognitive impairment in the context of lipopolysaccharide-induced chronic neuroinflammation and memory impairment, as well as in a rat model of vascular dementia $[23,24]$. Currently, however, there are no studies on the effect of glycyrrhizic acid with elderly mice in a cognitive dysfunction model using scopolamine $(1 \mathrm{mg} / \mathrm{kg})$.

The cholinergic system is regarded as an important factor in different types of dementia including $\mathrm{AD}$, since $\mathrm{ACh}$ plays an important role in cognitive function [25]. Deficits in the cholinergic transmission in cortical and hippocampal regions of brain can potentially influence all aspects of cognition and behavior [25]. Low levels of ACh are found in people with dementia, including patients with $\mathrm{AD}$, which is highly related to cognitive decline. Many studies suggest that AChE plays an important role in the regulation of diverse physiological reactions by hy- drolyzing the neurotransmitter ACh at cholinergic synapses. There are currently many attempts underway to find a treatment method that will increase ACh concentration in the brain by inhibiting AChE to improve cognitive function in patients with dementia. Several AChE inhibitors, such as tacrine, donepezil, rivastigmine, and carbamates in hospital are used to treat AD. Moreover, there are many studies investigating the hippocampal region of the brain in an attempt to find candidate drugs to improve memory or treat $\mathrm{AD}$ [26-29]. We observed that pretreatment with glycyrrhizic acid (10 mg/kg or $20 \mathrm{mg} /$ $\mathrm{kg}$ ) could decrease the AChE activity in the hippocampal region of the brain in scopolamine-induced cognitive impairment mice models. Indeed, it has been reported that glycyrrhizic acid could effectively lower the concentration of AChE, which is consistent with the results of the present study [30,31].

Free radicals derived from oxygen, nitrogen, and sulfur compounds are highly reactive molecules due to the presence of unpaired electrons. Free radicals cause oxidative stress and damage to DNA, RNA, proteins, carbohydrates, and lipids. Many studies have demonstrated a correlation between oxidative stress and various diseases; therefore, numerous drugs and methods have studied to alleviate the symptoms of diseases, linked to oxidative damage, by controlling antioxidant enzymes [32]. Our results showed that glycyrrhizic acid could effectively increase levels of SOD and CAT enzymes. Oxidative stress and antioxidant systems play an important role in pathophysiological changes in the brain. The activity of SOD is a sensitive indicator of the reduction of oxidative damage by superoxide anions that form hydrogen peroxide and reduce toxicity. CAT is a representative enzyme among antioxidants, and CAT breakdown of hydrogen peroxide protects tissues from reactive hydroxyl radicals [32]. There are many studies on improvement of memory function by suppressing the concentration of ACh enzyme and increasing the antioxidant enzyme.

We also investigated the effect of glycyrrhizic acid $(20 \mathrm{mg} /$ $\mathrm{kg}$ ) on protein expression of mitogen-activated protein (MAP) kinases, including JNK, ERK, and p38, using western blotting. It was confirmed that glycyrrhizic acid $(20 \mathrm{mg} / \mathrm{kg})$ increased phosphorylation of ERK and JNK proteins reduced by scopolamine $(1 \mathrm{mg} / \mathrm{kg})$. These MAP kinases play critical roles in regulating neural plasticity and inflammatory responses through 3 separate signaling pathways. Indeed, ERK and JNK signal transduction pathways are closely linked with learning and memory functions [33].

In summary, among the main bioactive components of $G$. 
uralensis, glycyrrhizic acid improved short-term memory through increased phosphorylation of ERK and JNK proteins. Also, it was associated with decreased activity of AChE and increased activity of SOD and CAT enzymes. These results suggest that glycyrrhizic acid has a neuroprotective effect on cognitive function in scopolamine-induced cognitive impairment.

\section{AUTHOR CONTRIBUTION STATEMENT}

- Conceptualization: SKK

- Formal Analysis: JYB, HKP

- Investigation: JYB, $H K P$

- Methodology: JYB, HKP

- Project Administration: JYB

-Writing - Original Draft: SKK

- Writing - Review \& Editing: SKK

\section{REFERENCES}

1. Bondi MW, Edmonds EC, Salmon DP. Alzheimer's disease: past, present, and future. J Int Neuropsychol Soc 2017;23:818-31.

2. Wang L, van Belle G, Crane PK, Kukull WA, Bowen JD, McCormick WC, et al. Subjective memory deterioration and future dementia in people aged 65 and older. J Am Geriatr Soc 2004;52: 2045-51.

3. Yang SH. Cellular and molecular mediators of neuroinflammation in Alzheimer disease. Int Neurourol J 2019;23:S54-62.

4. Ferri CP, Prince M, Brayne C, Brodaty H, Fratiglioni L, Ganguli M, et al. Global prevalence of dementia: a Delphi consensus study. Lancet 2005;366:2112-7.

5. Kim KW, Park JH, Kim MH, Kim MD, Kim BJ, Kim SK, et al. A nationwide survey on the prevalence of dementia and mild cognitive impairment in South Korea. J Alzheimers Dis 2011;23:281-91.

6. Michalowsky B, Kaczynski A, Hoffmann W. The economic and social burden of dementia diseases in Germany-A meta-analysis. Bundesgesundheitsblatt Gesundheitsforschung Gesundheitsschutz 2019;62:981-92.

7. Briggs R, Kennelly SP, O’Neill D. Drug treatments in Alzheimer's disease. Clin Med (Lond) 2016;16:247-53.

8. Eshkoor SA, Hamid TA, Mun CY, Ng CK. Mild cognitive impairment and its management in older people. Clin Interv Aging 2015; 10:687-93.

9. Shabani S, Mirshekar MA. Diosmin is neuroprotective in a rat model of scopolamine-induced cognitive impairment. Biomed Pharmacother 2018;108:1376-83.
10. Mochida K, Sakurai T, Seki H, Yoshida T, Takahagi K, Sawai S, et al. Draft genome assembly and annotation of Glycyrrhiza uralensis, a medicinal legume. Plant J 2017;89:181-94.

11. Asl MN, Hosseinzadeh H. Review of pharmacological effects of Glycyrrhiza sp. and its bioactive compounds. Phytother Res 2008; 22:709-24.

12. Fiore C, Eisenhut M, Krausse R, Ragazzi E, Pellati D, Armanini D, et al. Antiviral effects of glycyrrhiza species. Phytother Res 2008;22: 141-8.

13. Kim JK, Oh SM, Kwon HS, Oh YS, Lim SS, Shin HK. Anti-inflammatory effect of roasted licorice extracts on lipopolysaccharide-induced inflammatory responses in murine macrophages. Biochem Biophys Res Commun 2006;345:1215-23.

14. Oganesyan KR. Antioxidant effect of licorice root on blood catalase activity in vibration stress. Bull Exp Biol Med 2002;134:135-6.

15. Kim JS, Cheon S, Kim SW, Kim B, Kim H, Park KD, et al. Glycyrrhizic acid prevents astrocyte death by neuromyelitis optica-specific $\mathrm{IgG}$ via inhibition of $\mathrm{Clq}$ binding. Biochem Biophys Res Commun 2016;478:553-8.

16. Luo L, Jin Y, Kim ID, Lee JK. Glycyrrhizin attenuates kainic Acidinduced neuronal cell death in the mouse hippocampus. Exp Neurobiol 2013;22:107-15.

17. Hwang CK, Chun HS. Isoliquiritigenin isolated from licorice glycyrrhiza uralensis prevents 6-hydroxydopamine-induced apoptosis in dopaminergic neurons. Biosci Biotechnol Biochem 2012;76:53643.

18. Liu RT, Zou LB, Lu QJ. Liquiritigenin inhibits A $\beta 25$-35-induced neurotoxicity and secretion of A $\beta 1-40$ in rat hippocampal neurons. Acta Pharmacol Sin 2009;30:899-906.

19. Ko IG, Kim CJ, Kim H. Treadmill exercise improves memory by up-regulating dopamine and down-regulating D2 dopamine receptor in traumatic brain injury rats. J Exerc Rehabil 2019;15:50411.

20. Lee SS, Kim CJ, Shin MS, Lim BV. Treadmill exercise ameliorates memory impairment through ERK-Akt-CREB-BDNF signaling pathway in cerebral ischemia gerbils. J Exerc Rehabil 2020;16:4957.

21. Kim YM, Jin JJ, Lee SJ, Seo TB, Ji ES. Treadmill exercise with bone marrow stromal cells transplantation facilitates neuroprotective effect through BDNF-ERK1/2 pathway in spinal cord injury rats. J Exerc Rehabil 2018;14:335-40.

22. Ahn J, Um M, Choi W, Kim S, Ha T. Protective effects of Glycyrrhiza uralensis Fisch. on the cognitive deficits caused by beta-amyloid peptide 25-35 in young mice. Biogerontology 2006;7:239-47.

23. Liu W, Huang S, Li Y, Zhang K, Zheng X. Suppressive effect of glyc- 
yrrhizic acid against lipopolysaccharide-induced neuroinflammation and cognitive impairment in C57 mice via toll-like receptor 4 signaling pathway. Food Nutr Res 2019;63. https://doi.org/10.29219/fnr. v63.1516.

24. Guo J, Yang CX, Yang JJ, Yao Y. Glycyrrhizic acid ameliorates cognitive impairment in a rat model of vascular dementia associated with oxidative damage and inhibition of voltage-gated sodium channels. CNS Neurol Disord Drug Targets 2016;15:1001-8.

25. Ferreira-Vieira TH, Guimaraes IM, Silva FR, Ribeiro FM. Alzheimer's disease: targeting the cholinergic system. Curr Neuropharmacol 2016;14:101-15.

26. Lee JM, Baek SS, Kim TW, Park HS, Park SS, Park JM, et al. Preischemic treadmill exercise improves short-term memory by inhibiting hypoperfusion-induced disruption of blood-brain barrier after bilateral common carotid arteries occlusion. J Exerc Rehabil 2019;15:370-6.

27. Lee JM, Ji ES, Kim TW, Kim CJ, Shin MS, Lim BV, et al. Treadmill exercise improves memory function by inhibiting hippocampal apoptosis in pilocarpine-induced epileptic rats. J Exerc Rehabil 2018;14:713-23.

28. Shin MS, Kim TW, Park SS, Ko IG, Kim CJ, Kim M, et al. Long- term surgical and chemical castration deteriorates memory function through downregulation of PKA/CREB/BDNF and c-Raf/ MEK/ERK pathways in hippocampus. Int Neurourol J 2019;23: $116-24$.

29. Kim SE, Ko IG, Ji ES, Jin JJ, Hwang L, Kim SH, et al. Treadmill exercise alleviates circadian rhythm disruption-induced memory deficits by activation of glucocorticoid receptor and brain-derived neurotrophic factor-dependent pathway. Int Neurourol J 2019;23: S40-9.

30. Abdel Bar FM, Elimam DM, Mira AS, El-Senduny FF, Badria FA. Derivatization, molecular docking and in vitro acetylcholinesterase inhibitory activity of glycyrrhizin as a selective anti-Alzheimer agent. Nat Prod Res 2019;33:2591-9.

31. Schwarz S, Lucas SD, Sommerwerk S, Csuk R. Amino derivatives of glycyrrhetinic acid as potential inhibitors of cholinesterases. Bioorg Med Chem 2014;22:3370-8.

32. Khan RA, Khan MR, Sahreen S. Brain antioxidant markers, cognitive performance and acetylcholinesterase activity of rats: efficiency of Sonchus asper. Behav Brain Funct 2012;8:21.

33. Peng S, Zhang Y, Zhang J, Wang H, Ren B. ERK in learning and memory: a review of recent research. Int J Mol Sci 2010;11:222-32. 